\title{
An Unusual Presentation of a Central Giant Cell Granuloma and Initial Treatment with Intralesional Steroids- A Case Report and Review of the Literature
}

\author{
Richard M Graham, Murray E Foster, David Richardson
}

\section{ABSTRACT}

A case of a 6 year-old boy is presented with an extensive intraoral central giant cell granuloma, which was initially thought to be a lesion of odontogenic origin. Central giant cell granuloma is an unusual lesion to be found within the oral cavity. Treatment ranges from radical surgical resection to conservative approaches, such as the one presented, with intralesional steroid injections. We would agree with previous work that this as a viable treatment adjunct and possible alternative to surgery for central giant cell granuloma of the jaws.

\section{Contact Author}

Dr. Richard M. Graham

E-mail : grahamrm2@yahoo.co.uk

\section{Key Words:}

$\longrightarrow$ iant cell granuloma was first described by Jaffe in 1953(1). Two types are recognised: peripheral and central (2). A peripheral giant cell granuloma is otherwise known as a Giant cell epulis and is a non-neoplastic lesion and is due to the proliferation of granulation tissue. According to several authors, granulation tissue in this situation consists of $(2,3,4,5,6,8,9)$ :

- Macrophages: These become fused and form multinucleate giant cells, which are osteoclast-like.

- Friable neo-vasculature.

- Mesenchymal cells, Fibroblasts and fibrous tissue / stroma and occasional trabeculae of woven bone.

- Haemosiderin.

It tends to occur on the gingiva or alveolar mucosa and appears as a soft red / blue, haemorrhagic, painless, nodular swelling. A giant cell granuloma is termed as central, if the same lesion originates within the mandible or maxilla(5) and can be seen on radiographs as a unilocular or multilocular radiolucency, with or without peripheral cortication (5-12).

The central lesion is less common than the peripheral type (5), it can be associated with perforation of the cortical plate(s) (7) and will then present like a peripheral lesion (3). Central giant cell granulomas are reactive, hyperplasic lesions (3) and may also be developmental anomalies closely related to the aneurysmal bone cyst or true benign neoplasms $(4,7)$, therefore, their true nature and mechanism of onset is still unknown $(4,7,9)$.
As they can perforate neighbouring structures, displace teeth $(7,9,12)$ and cause local tissue destruction $(5,6,9,13)$, they are now believed not to be strictly reparative in nature (8) and are probably more a neoplastic lesion, therefore the correct term for these is Giant Cell Tumour (8).

\section{Case History}

A 6 year-old boy was referred to the Oral and Maxillofacial Surgery department by his General Dental Practitioner, with a well localised palatal and buccal, painless, swelling of the right side of the premaxilla, which also involved the maxillary deciduous central and lateral incisors, that had apparently arisen rapidly over just 2 days. There was no significant medical history and a family history of his mother having multiple unerupted teeth.

\section{On Examination}

An obvious facial swelling in the right premaxillary region was present, the maxillary deciduous central and lateral incisors were submerged into and encased by a $3 \mathrm{~cm} \times 1.5 \mathrm{~cm}$ blue coloured, soft and ovoid lesion, causing both buccal and palatal alveolar expansion. A provisional diagnosis of a lesion, possibly a cyst, likely of odontogenic origin, was made at this time, see Fig. 1 and 2. Also an anterior occlusal radiograph was taken at this time which confirmed the presence of a large unilocular mixed radiolucent / radio-opaque lesion, causing buccal plate expansion and erosion and with displaced teeth buried within it. 


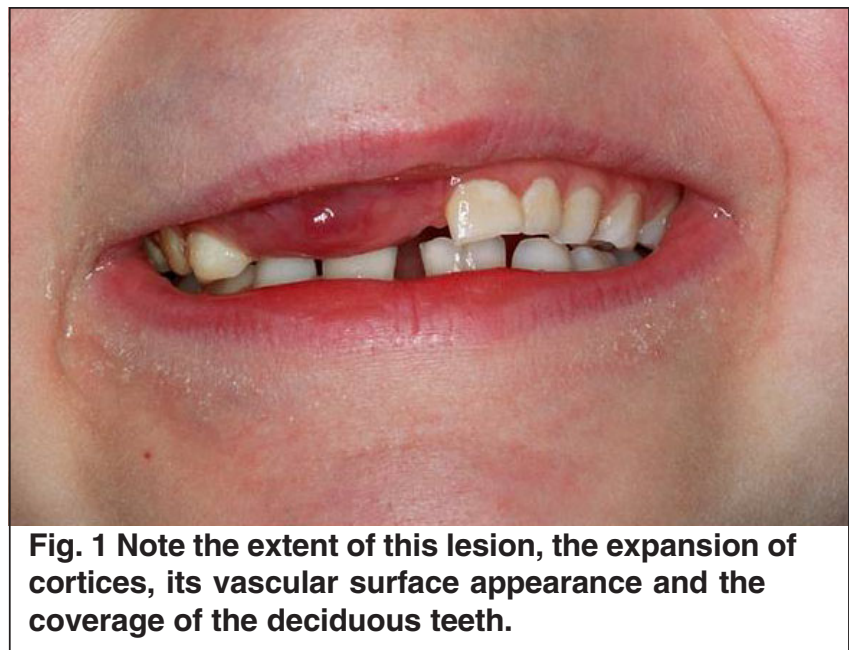

\section{Treatment}

Under a general anaesthetic this lesion was biopsied, and then the mobile and displaced maxillary deciduous central and lateral incisors were identified and extracted. Also a Whitehead's varnish ribbon gauze pack was placed to control profuse haemorrhage and act as an antiseptic.

\section{Progress}

The pack was removed in stages, over a 6-week period, in the

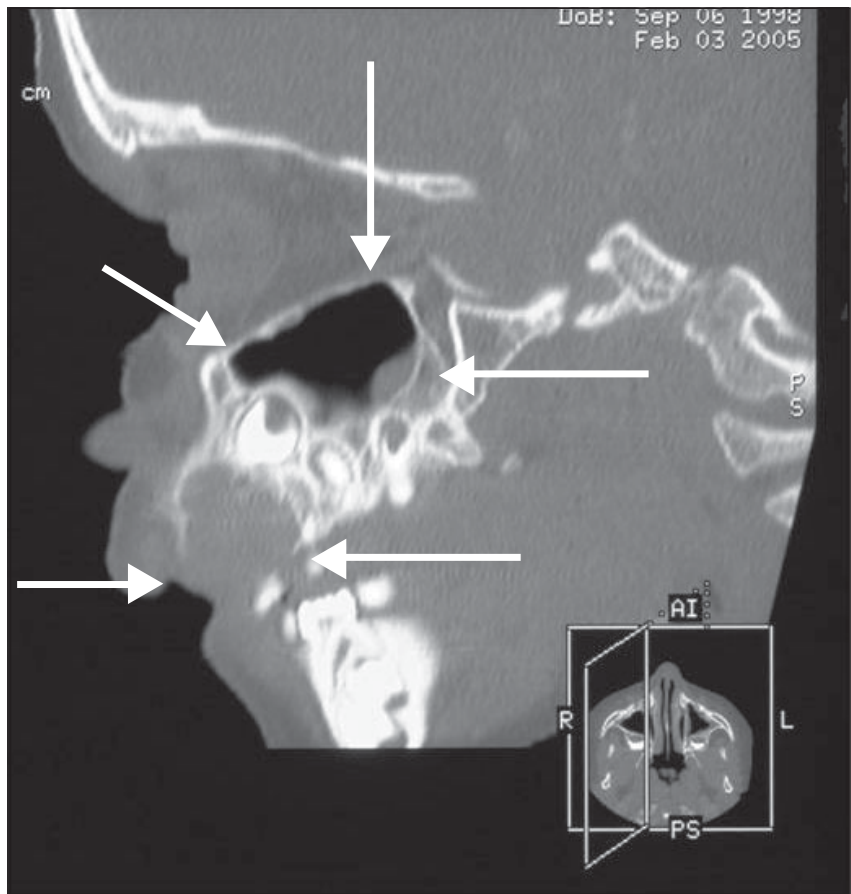

Fig. 3: 3-dimensional C.T. scans of the maxillary lesion showing the extensive nature into the alveolus and majority of the hard palate, extensive bony erosion in all planes and displacement of the right maxillary permanent central incisor through the floor of the nose. Arrows indicate the periphery of the lesion.

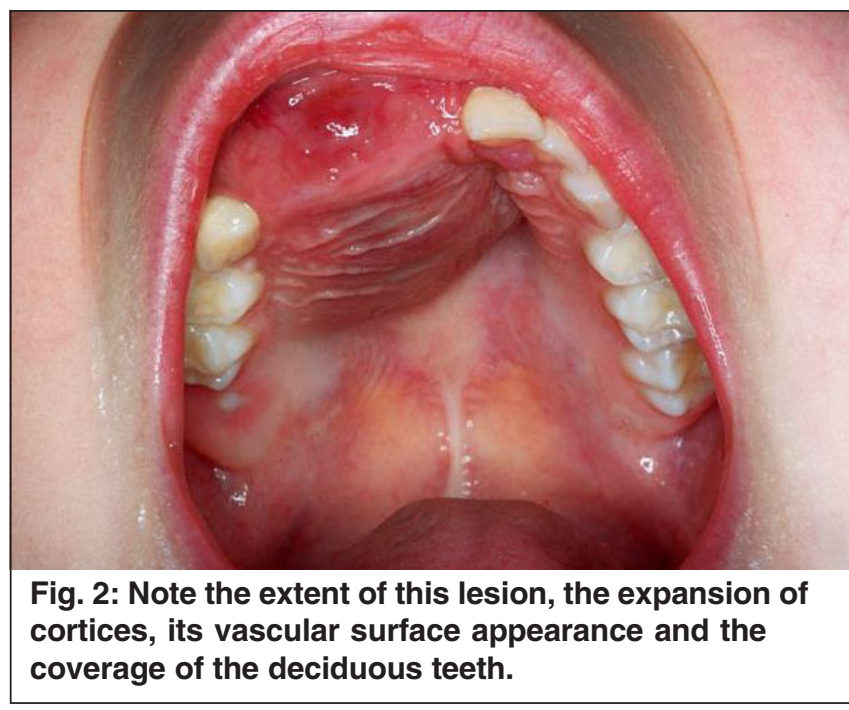

outpatient department to allow healing by secondary intention. The initial histopathological diagnosis was reported as: Giant Cell Epulis / Peripheral Giant Cell (Reparative) Granuloma, with no evidence of malignancy. Over a 3 month period, the lesion appeared to improve initially, but towards the end of this period there was clear evidence of progression and more extensive bone loss. Therefore, a 3-dimensional C.T. scan was arranged at a specialised children's hospital, (as shown in Fig. 3 and 4) and a further larger biopsy was performed under general anaesthesia, with a view to complete lesion enucleation.

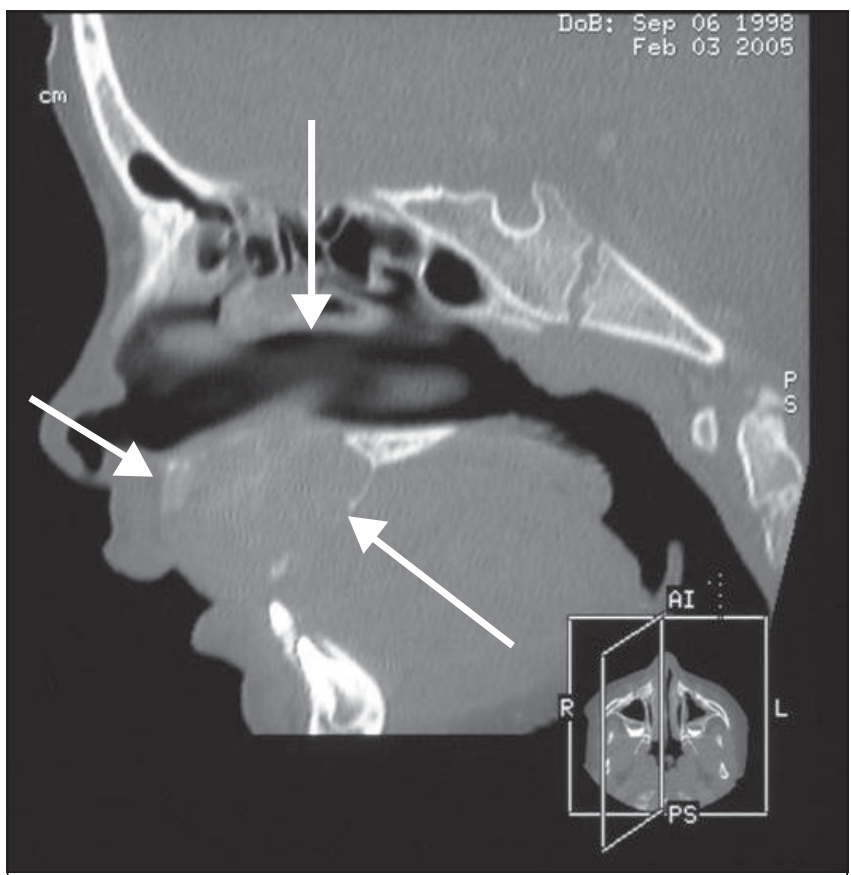

Fig. 4: 3-dimensional C.T. scans of the maxillary lesion showing the extensive nature into the alveolus and majority of the hard palate, extensive bony erosion in all planes and displacement of the right maxillary permanent central incisor through the floor of the nose. Arrows indicate the periphery of the lesion. 


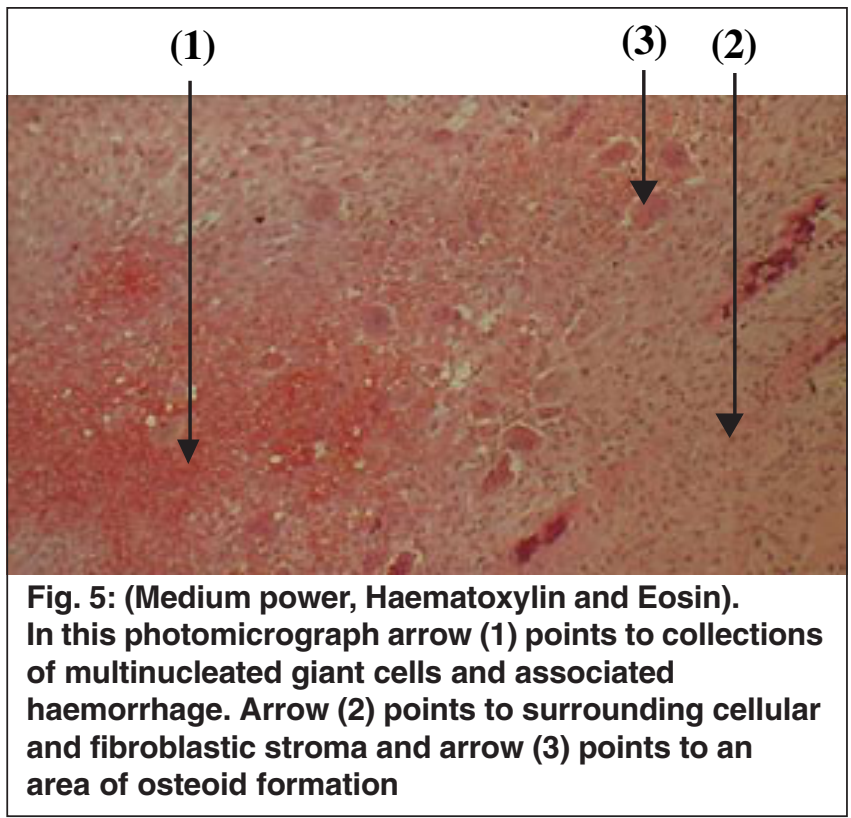

However, the extensive bony erosion of the hard palate and nasal floor was such that a significant oro-nasal communication might result following enucleation, which would require complex reconstruction.

Interestingly, the subsequent histopathological diagnosis was confirmed as: Central Giant Cell (Reparative) Granuloma (see Fig. 5 and 6).

A Brown tumour of Hyperparathyroidism had been excluded by normal levels of bone biochemistry (serum calcium, phosphorous and alkaline phosphatase) and Parathyroid hormone level. In view of a likely oro-nasal communication, an alternative treatment to radical curettage was attempted.

Under a general anaesthetic once every 2 weeks for 12 weeks, injections were placed into the lesion. These comprised of an equal mixture of a local anaesthetic solution (plain Levobupivacaine) and a steroid solution $(25 \mathrm{mg}$ of Triamcinalone acetonide, on average, per injection).

2.5 months following the start of the intralesional injections, at a clinic review, clinical and radiographic appearances of new bone formation within the lesion were confirmed and further surgery was deferred at this stage, therefore, the intralesional steroids were preventing progression of the lesion (no increase in size) and stimulating new bone formation within it. Therefore one last injection was given.

However, at almost 4 months following the start of the injections, the continued lack of complete involution and slow progress of bone reformation lead to a discussion with the parents regarding other possible treatment options. Angiography was suggested as a next step in view of its

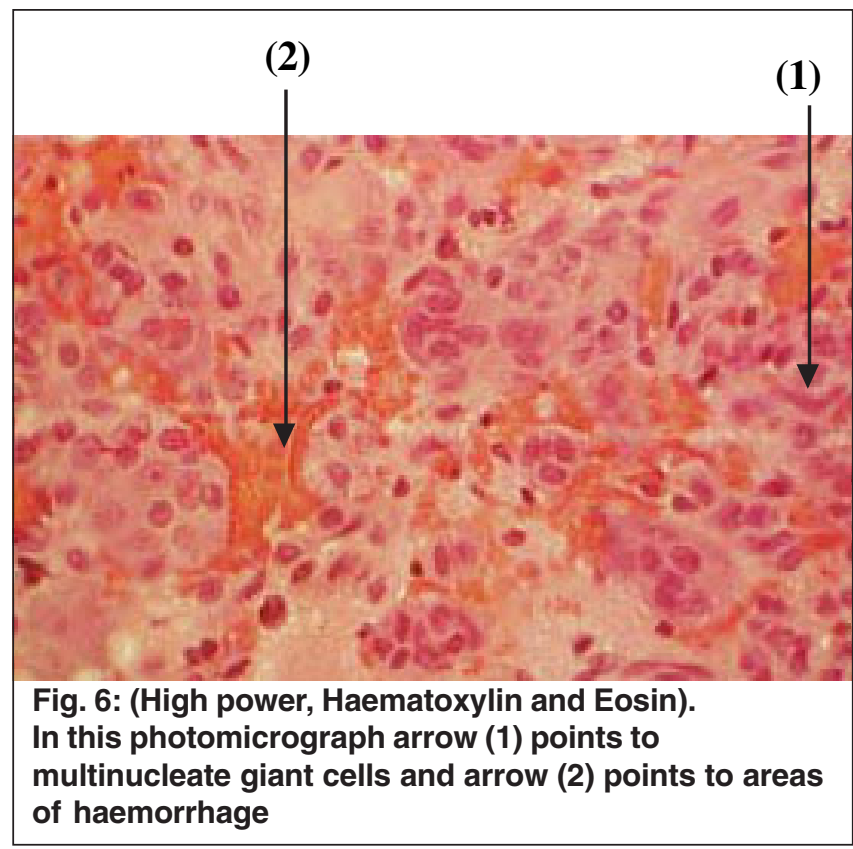

vascular nature, to rule out an arteriovenous malformation (despite biopsy results), as it had bled so profusely on biopsy.

He was therefore referred to another regional paediatric Maxillofacial unit, because angiography facilities were not available at the original hospital. However, at the unit to which he was referred, it was not possible to perform angiography and therefore complete removal of the lesion was in fact recommended. Under a general anaesthetic at this unit, the lesion was exposed via both buccal and palatal mucoperiosteal flaps and it was found to be extending into the hard palate associated with a small nasal mucosal dehiscence. The lesion was of a vascular, gelatinous and gritty consistency and was smaller than it had been on first presentation. A cleavage plane was identified between the abnormal tissue and the mucoperiosteum, the lesion was completely enucleated and a small nasal mucosal repair was performed. Fortunately, no further bony or soft tissue reconstruction was required at this stage and he made a good post-operative recovery.

Histopathological examination of the tissue confirmed a giant cell reparative granuloma, as before, but interestingly many irregular and chaotic bony trabeculae were also identified, confirming the reparative action of the intralesional steroid treatment. At a 3-month review appointment good healing was present with no lesion recurrence, however, he continues to be kept under long-term review arrangements.

\section{Discussion}

What is unusual about our case?

- It was initially thought to be an odontogenic lesion, but proved to be a solid non-odontogenic lesion, from bone.

- Whilst central giant cell granulomas may occur in children, 
they are unusual at the age of our male patient $(2,8,11,12)$.

- $65 \%$ of central giant cell granulomas occur in females $(9,11,12)$.

- Usually, the mandible is more commonly affected than the maxilla(2-4,7,9,11-14).

- In this case, although the lesion was ovoid in shape, it did not conform to the typical hourglass shape, i.e. an adjoining 'waist' between the teeth, as previously described(3).

- Central giant cell granulomas are seldom locally aggressive $(3,4)$. These types, such as this case, are rarely found in younger patients and tend to be in the maxilla(4) and are associated with pain, cortical perforation, root resorption and a poorly defined radiological margin $(7,11,12)$.

- Curettage and surgical resection are the most common treatments for central giant cell granulomas $(1,2,5-9,11,12,14)$ and usually lead to satisfactory results(3). This is in fact what happened to this patient's lesion, but interim intralesional steroids definitely helped to prevent the progression of this lesion and avoided extensive bony destruction. Nonetheless, lesion recurrence can occur in $11-49 \%$ of cases(9), therefore, this patient remains under close review.

\section{Why consider intralesional steroids?}

Given the extent, bony destruction and position of this lesion and the age of this patient, a less invasive course of treatment was adopted. Several authors state that because it is a benign process in a child that is still growing and remodelling, that less radical treatment alternatives are desirable $(5,13)$.

Some work on alternative therapies, for central giant cell granulomas, has already been done. This includes:

- Radiation. This may promote malignancy, so is no longer recommended $(7,14)$.

- Systemic calcitonin injections or infusions and/or nasal sprays $(2,8,9,12)$. These can be required for long periods (up to 21 months) to achieve healing(8) and can be associated with unpleasant side effects(9). There is also the potential for treatment resistance(9).

- Methyl prednisolone acetate treatment. Good results have been reported (15), but increase in lesion size with this has also been reported (9).

- Interferon-alpha. Experience with this treatment modality for central giant cell granulomas is limited(16), but intralesional bone formation is reported(17). However, since interferon therapy has considerable side effects (18), it should only be used if other treatment options fail(16) and as an adjuvant to surgical enucleation(19), not alone.

Several other authors have reported excellent initial results and stable long-term results (bony in-fill of defects and eventual lesion resolution) in particular with intralesional injections of the steroid Triamcinalone Acetonide(7,11-14). Indeed, partial bony infill did occur in the lesion of the patient presented, as a consequence of the intralesional Triamcinalone Acetonide injections, as irregular and chaotic bony trabeculae were identified in the final enucleation specimen.

\section{How do steroids work?}

It has been shown that osteoclast-like multinucleated giant cells decrease their lysosomal protease extracellular production, which mediates bone resorption, in the presence of steroids (12). Also, in animal experiments, steroids have been shown to induce apoptosis in osteoclasts (12). These mechanisms result in a net decrease in bone resorption and a net increase in bone formation.

\section{Success with steroids}

Body et al. first suggested the treatment of Giant Cell Granulomas with systemic steroids in 1981(20); their lesion responded, but treatment had to be stopped due to side effects. Intralesional injection of corticosteroid is preferable to systemic administration, in order to avoid systemic side effects and obtain a high-localised tissue concentration (6). So, in 1988, Jacoway et al. suggested intralesional treatment with steroids for giant cell granulomas, the growth of the lesion was arrested and gradual bony regeneration into the defect occurred after 6-weekly injections (21). Radiographic changes to a more bony trabecular pattern may be noted after 3 to 6 months (6).

Successful examples of the use of intralesional steroids are as follows: In Kurtz's case; 12 injections of intralesional Triamcinalone Acetonide were given, in total, for a $15 \mathrm{~cm}^{2}$ lesion, $150 \mathrm{mg}$ each for at least 6 of these, which resulted in complete re-ossification of the area affected by a central giant cell granulomas (11). In addition, Carlos et al. have reported 4 cases of central giant cell granulomas, which were treated successfully in the same way (the average dose was $25 \mathrm{mg}$ of Triamcinalone Acetonide for the paediatric patients) (12). Khafif et al.'s case of a central giant cell granuloma of the maxilla was successfully treated with intralesional corticosteroids; there was no lesion recurrence and the defect calcified (average dose of 40mg Triamcinalone Acetonide $+0.5 \%$ Bupivacaine weekly for 6 weeks)(5).

\section{How to use intralesional steroids for central giant cell granulomas}

The first priority is to exclude a Brown Tumour of Hyperparathyroidism (by blood tests) and a giant cell tumour / osteoclastoma (by biopsy) (11). Then, the Terry and Jacoway's Protocol (1994) is used, which consists of: equal parts of Triamcinalone acetonide $(10 \mathrm{mg} / \mathrm{ml})$ and local anaesthetic ( $0.5 \%$ Bupivacaine with 1 in 200,000 Adrenaline), at a dose of $2 \mathrm{mls}$ of Triamcinalone Acetonide per $2 \mathrm{~cm}$ of radiolucency (6), for our lesion this equalled $3 \mathrm{mls}$ or $30 \mathrm{mg}$ of Triamcinalone Acetonide. This is injected throughout the lesion and a total of 6 separate doses are used $(5,6)$. 
This protocol can be given pre-operatively, for large lesions, to decrease their size (11). Intralesional steroids are less invasive, low risk and do not preclude later surgery (11). However, the long-term outcome of this form of treatment has yet to be defined (11) which would require a controlled study (8).

\section{Conclusion}

It has been observed that the more aggressive central giant cell granuloma lesions respond to intralesional steroids with a fast reparative action (12). The doses used and duration have not been shown to result in any adrenal suppression (12). Intralesional steroids for central giant cell granulomas are a low cost treatment and a reasonable adjunct, if not alternative, to surgery, especially where vital structures may be compromised (12) and where facial growth may be impaired by surgery (5). In this case, intralesional steroids have helped to control the destructive and extensive nature of the disease, such that although further surgery was eventually required, it was of a significantly less extensive nature, requiring only enucleation and closure as opposed to widespread ablation and complex reconstruction, which would have been required if the lesion had been allowed to progress.

\section{Acknowledgement}

The authors would like to thank the Oral Pathology Unit, University Dental Hospital of Manchester, for reviewing the histopathology for this lesion.

\section{THE AUTHORS}

\section{Dr. Richard M. Graham}

BDS, FDSRCS, MB ChB, MRCS, FRCS (OMFS)

Specialist Registrar

Oral and Maxillofacial Surgery Department

North Manchester General Hospital

grahamrm2@yahoo.co.uk, Tel: (UK) 01617954567

\section{Dr. Murray E. Foster}

BDS, MDSc, FDSRCS, FFDRCSI, MB BCh, FRCS

Consultant

Oral and Maxillofacial Surgery Department

North Manchester General Hospital

\section{Mr. David Richardson}

FDSRCS, FRCS

Consultant

Regional Maxillofacial Unit

Royal Aintree Hospital, Liverpool

Or

Alder Hey Children's Hospital, Liverpool

\section{References}

1. Jaffe HL. Giant cell reparative granuloma, traumatic bone cyst and fibrous (fibro-osseous) dysplasia. Oral Surg 1953; 6: 159175.

2. Harris M. Central giant cell granulomas of the jaws regress with calcitonin therapy. Br J Oral Maxillofac Surg 1993; 31: 89-94.

3. Soames JV, Southam JC. Oral Pathology. New York, USA: Oxford University Press, 2005; pp.103-6, 251, 255-6.

4. Carinci F, Piattelli A, Martinelli M, Palmieri A, Rubini C, Fioroni M, et al. Genetic profiling of central giant cell granuloma of the jaws. J Craniofac Surg 2005; 16: 399-407.

5. Khafif $A$, Krempl G, Medina JE. Treatment of giant cell granuloma of the maxilla with intralesional injection of steroids. Head and Neck 2000; 22: 822-825.

6. Terry BC, Jacoway JR. Management of central giant cell lesions. Oral Maxillofac Surg Clin North Am 1994; 6: 579-600.

7. Adornato MC, Paticoff KA. Intralesional corticosteroid injection for treatment of central giant-cell granuloma. J Am Dent Assoc 2001; 132: 186-190.

8. Pogrel MA, Regezi JA, Harris ST, Goldring SR. Calcitonin treatment for central giant cell granulomas of the mandible: Report of two cases. J Oral Maxillofac Surg 1999; 57: 848-853.

9. de Lange J, Rosenberg AJWP, van den Akker HP, Koole R, Wirds JJ, van den Berg $\mathrm{H}$. Treatment of central giant cell granuloma of the jaw with calcitonin. Int J Oral Maxillofac Surg 1999; 28: 372-6.

10. Hensyl WR, Felscher H. Stedman's Medical Dictionary. London: Williams and Wilkins, 1990; pp.668, 1653.

11. Kurtz M, Mesa M, Alberto P. Treatment of a giant cell lesion of the mandible with intralesional glucocorticosteroids. Oral Surg Oral Med Oral Pathol Oral Radiol Endod 2001; 91: 636-7.

12. Carlos R, Sedano HO. Intralesional corticosteroids as an alternative treatment for giant cell granuloma. Oral Surg Oral Med Oral Pathol Oral Radiol Endod 2002; 93: 161-6.

13. Rajeevan NS, Soumithran CS. Intralesional corticosteroid injection for central giant cell granuloma. Int J Oral Maxillofac Surg 1998; 27: 303-4.

14. Kermer C, Millesi W, Watzke IM. Local injection of corticosteroids for central giant cell granuloma. Int J Oral Maxillofac Surg 1994; 23: $366-8$.

15. Scaglietti $O$, Marchetti $P G$, Bartolozzi $P$. The effects of methylprednisolone acetate in the treatment of bone cysts. J Bone Joint Surg Br 1979; 61: 200-4.

16. de Lange J, van den Akker HP. Response to letter to the editor: Management of giant cell lesions. Int J Oral Maxillofac Surg 2006 35: 1076.

17. Busaidy B, Wong MEK, Herzog C, Flaitz C, Marchena J Eftekhari F. Alpha interferon in the management: early experiences. $J$ Oral Maxillofac Surg 2002; 60 (Suppl.): 86-7.

18. Goldman KE, Marshall MK, Alessandrini E, Bernstein ML. Complications of alpha-interferon therapy for aggressive giant cell lesion of the maxilla. Oral Surg Oral Med Oral Pathol Oral Radiol Endod 2005; 100: 285-91.

19. Kaban LB, Dodson TB. Letter to the editor: Management of giant cell lesions. Int J Oral Maxillofac Surg 2006; 35: 1074-5.

20. Body JJ, Jortay AM, De Jager R, Ardichvili D. Treatment with steroids of a giant cell granuloma of the maxilla. J Surg Oncol 1981; 16: 7-13.

21. Jacoway JR, Howell FV, Terry BC. Central giant cell granuloma - an alternative to surgical therapy. Oral Surg 1988; 5: 572. 